\title{
MATIZES DO PENSAMENTO POLÍTICO NORTE-AMERICANO NA VIRADA CONSERVADORA DE 1970
}

\author{
Maria Ribeiro do Valle*
}

\begin{abstract}
Este artigo examina de que forma o revigoramento da excepcional experiência histórica americana aparece como solução para alguns dos principais neoconservadores, sendo emblemáticos Nathan Glazer e Irving Kristol, frente à “queda” do império americano, que tem início nos anos 1960 e 1970, depois de sua ascensão no período da Guerra Fria, os chamados 25 anos gloriosos. Constatamos que a argumentação desses autores está enraizada na retomada da retórica reacionária como antídoto à decadência da virtude americana supostamente provocada pelo comunismo, pelo movimento da contracultura e pelo alegado efeito perverso do welfare state.

PALAVRAS-CHAVE: neoconservadores, excepcionalidade americana, pós 25 anos gloriosos, contracultura, welfare state.
\end{abstract}

\section{BREVE HISTÓRICO: o pós 25 gloriosos e a virada neoconservadora}

Nos Estados Unidos do pós-guerra, as teorias ou enquadramentos analíticos, como a tese da convergência das sociedades industriais, a teoria da decadência e da contrainsurgência, a teoria $d a$ modernização e a teoria da ingovernabilidade marcaram profundamente o perfil das ciências sociais norte-americanas e o de outros países, devido à sua posição hegemônica e, por isso, definidora da constituição do mundo contemporâneo. Notamos, assim, uma não-linearidade do posicionamento político dos EUA, levando os seus analistas políticos a passarem por uma guinada que vai de seu otimismo inicial, nos anos de 50 - quando buscavam compreender a natureza das sociedades desenvolvidas, para vislumbrar os caminhos de sua

* Doutora pelo Departamento de Ciências Sociais Aplicadas da Faculdade de Educação da Unicamp. Professora do Departamento de Sociologia da Faculdade de Ciências e Letras da Unesp - campus de Araraquara.

Rodovia Araraquara-Jaú, km 1 - Caixa Postal 174 CEP: 14800-901 - Araraquara-SP. cso@fclar.unesp.br possível reforma, em que a assistência técnica norte-americana ganhava primazia -, para uma análise cética e realista dos anos 60, decorrente da crise financeira global e das consequências do colapso sistêmico do Ocidente, aí incluída a posição hegemônica dos EUA.

A excepcionalidade americana voltará à tona devido às implicações domésticas provocadas pelo abalo de sua hegemonia, levando à necessidade de sua própria redefinição política, econômica, social e cultural, para revitalizar seu poderio. E, por outro lado, pelas consequências do ponto de vista da política externa, ou seja, da desigualdade entre as nações. Elas podem acompanhar a marcha para o progresso americano, ou emerge, com as teorias em pauta, a ratificação de suas disparidades?

À primeira vista, a falência da defesa da expansão da democracia na América parece levar, em alguns discursos, a uma visão ainda mais etnocêntrica dos EUA, indicando que, ao contrário do que pensavam antes alguns modernizadores, as demais nações não são culturalmente preparadas para o domínio alcançado pelos americanos. 
Está em pauta a virada conservadora dos anos 70, que é desencadeada pela crise dos Estados Unidos, que já se esboçava no final dos anos 60, depois de sua ascensão no período da Guerra Fria, os chamados 25 anos gloriosos. Destaca-se, nesse período, a crise econômica que não atinge somente a classe capitalista que vive dos negócios, nem sequer a classe trabalhadora estabelecida. Os grandes perdedores são os imigrantes e os trabalhadores não-brancos, e, em último lugar, a classe trabalhadora dos países pobres, sem controle de matérias-primas. Os anos 70 marcam o fim da era da abundância, o que afeta a maioria da população, devido, principalmente, aos seguintes fatores: a impossibilidade do controle dos preços das matérias primas por alguns países pobres, a condição sem saída da energia térmica, por ser cara, e da nuclear, por ser perigosa, a impossibilidade de manter o industrialismo a todo custo, a opção pelo extraordinário poder e corrupção das empresas multinacionais e a desvalorização do dólar como moeda da ordem capitalista, dentre outros (Miguel, 1978, p. 26).

Segundo Miguel, pode-se dizer que "o ano de 1973 é a data em que a crise toca fundo” (1978, p. 27). Nesse ano termina a Guerra do Vietnã e tem lugar a crise de Watergate, ou seja, é o fim de uma época de solidez das instituições políticas. Nesse mesmo ano, os árabes decidem aumentar o preço do petróleo, rompendo o equilíbrio econômico e político do mundo capitalista. Começa-se a notar os primeiros efeitos da economia da escassez nos Estados Unidos. O dólar deixa de ser o padrão monetário universal, e a inflação se torna endêmica. A era de ouro do imperialismo americano parece ameaçada, enquanto começa a despontar uma nova forma de domínio internacional: o das empresas multinacionais, basicamente norte-americanas, mas também europeias e japonesas (p. 27).

Os anos 70, nos Estados Unidos, têm suscitado uma literatura de revisão e análise sobre um momento crítico marcado por problemas econômicos, políticos, culturais e sociais. Está em pauta a virada conservadora dos anos 70, quando os analistas políticos e sociais - os neoconservadores - começam a propor seus próprios estudos como instrumentos de intervenção na realidade, defendendo o sistema capitalista, anteriormente combatido por eles. Nessa década tais intelectuais passam a ocupar importantes cargos políticos no governo, frequentando a Casa Branca e sendo agraciados com atenção pública, subvenções e apoio do governo (Jacoby, 1990). A esfera pública passa a ser menos um mercado livre de ideias do que um mercado puro e simples. Eles abandonaram a política pela administração e pelo êxito pessoal, aceitando, seus postos nas burocracias do Estado ou da mídia (1990).

Daniel Bell, S. M. Lipset, D. P. Moynihan, N. Glazer, James Q. Wilson, Paul H. Weaver e Arthur Schlesinger, nos anos 70, são professores universitários que tinham militado na esquerda ou que pertenciam à ala mais liberal do Partido Democrata. Os sete pertencem ao grupo de Harvard, em departamentos de ciências sociais. Quase todos eles pertencem à geração que nasce em torno de 1920, ou seja, os mais jovens da Guerra Civil Espanhola e os mais velhos do Macarthismo. Nos anos 50, não apenas Glazer, Hook, Feuer e Lipset, mas Irving Kristol, Lionel Trilling, Daniel Bell, Leslie Frieldler e vários outros renegaram seu passado esquerdista (Jacoby, 1990), passando a criticar com veemência a Nova Esquerda, o rechaço do sistema capitalista e a liberação das relações interpessoais - sexo, drogas, roupas (Miguel, 1978, p.201-202).

Alguns neoconservadores, como Glazer e Kristol, foram progressistas e guinaram para a direita a partir da retomada de algumas das importantes teses do credo conservador: o rechaço às grandes abstrações na política e a interpretação da história estadunidense do século XX como a realização de um processo de decadência sustentado pelas inovações culturais e pelo comunismo. Os neoconservadores têm, assim, como principais alvos a contracultura e as políticas sociais intervencionistas empreendidas inicialmente pelos governos Kennedy e Johnson, nos EUA da década de 1960, na política conhecida como Great Society. Sua crítica é direcionada à hegemonia progressista que tomou conta de seu país tanto no campo da política governamental quanto no campo da cultu- 
ra e às suas consequências ideológicas (Miguel, 1978).

A questão central enfrentada por esses intelectuais americanos que, a partir dos anos 70, parecem obcecados pela identidade dos EUA como nação, frente aos acontecimentos que colocam em xeque o imperialismo americano, é, segundo Miguel: "O capitalismo americano deve ser aceito como uma ordem social permanentemente desigual que é incompatível com o cumprimento dos objetivos democráticos para todo o mundo?” (1978, p. 31)

Diante dessa questão, os escritos de Nathan Glazer e Irving Kristtol, destacados neoconservadores, demonstram um grande ceticismo a respeito da democracia não apenas como uma forma política extensível aos países pobres como também como uma ameaça aos pilares da república americana frente à crise econômica e ética que tem origem nos anos 70 .

Neste artigo, buscamos, então, fazer um exame dos discursos e das retóricas de Nathan Glazer e Irving Kristol, ou seja, visamos a reconstruir seus argumentos a partir de sua própria lógica interna, como um exercício que procura fazer aparecer os seus pressupostos e os seus posicionamentos nem sempre explícitos. Procuramos também analisar as consequências dessa argumentação, com o intuito de averiguar a posição em que se colocam esses autores no espectro ideológico. O nosso objetivo foi o de compreender o fortalecimento de tais discursos, para dar subsídios a uma crítica sociológica que parece ter concomitantemente enfraquecido na conjuntura que sucede uma crítica veemente ao capitalismo feita pela contracultura. Os movimentos de protesto que tiveram seu ápice em 1968 expressavam:

... uma crítica social de feição marxista clássica e reivindicações de um tipo muito diferente, com apelos à criatividade, ao prazer, ao poder da imaginação, à liberação referente a todas as dimensões da existência, à destruição da "sociedade do consumo”, etc. (Boltanski; Chiapello, 2009, p.19).

Pretendemos compreender, assim, por meio do espectro ideológico de Nathan Glazer e Irving
Kristol, a guinada da situação vivenciada e pensada em 68, que desaparece no final dos anos 60 e início dos anos 70, quando a crise do capitalismo provoca a emergência de um pensamento, o neoconservador, que visa a recompor o capitalismo. Eles parecem ter contribuído para o sucesso dessa empreitada, uma vez que seu objetivo será alcançado, pois o capitalismo passa a se deparar, cada vez mais, com menos dificuldades no plano ideológico, ao mesmo tempo em que os dispositivos críticos sociológicos disponíveis parecem não oferecer alternativa alguma de envergadura.

Ir até às origens do pensamento de dois autores expoentes do neoconservadorismo parece revelar-nos o olhar e o modo como os homens fazem sua história, pois, como intelectuais que ocupam postos governamentais, exercem um papel privilegiado na decisão dos acontecimentos sociais e políticos nos EUA. Nosso objetivo é mostrar, neste momento, que as coisas se deram assim, mas poderiam ter se enveredado por uma direção diferente. Acreditamos que, ao trazermos à tona a reconstrução da argumentação teórica dos neoconservadores, podemos contribuir para uma sociologia crítica, na medida em que ela pode voltar a contribuir para a realização da história justamente quando se posicionar ao lado da desnaturalização desses construtos ideológicos que pregam o sucesso do capitalismo, pretendendo sua validade geral.

Arriscaríamos afirmar que está no discurso de Nathan Glazer e Irving Kristol a origem do "novo espírito do capitalismo”, tematizado por Boltanski e Chiapello:

Para manter seu poder de mobilização, o capitalismo, portanto, deve obter recursos fora de si mesmo, nas crenças que, em determinado mo-
mento, têm importante poder de persuasão, nas ideologias marcantes, inclusive nas que lhe são hostis, inseridas no contexto cultural em que ele evolui. O espírito que sustenta o processo de acumulação, em dado momento da história, está assim impregnado pelas produções culturais que lhe são contemporâneas e foram desenvolvidas para fins que, na maioria das vezes, diferem completamente dos que visam a justificar o capitalismo (1999, p.53).

Contudo, ao ter um papel central para a formulação de um "novo espírito do capitalismo" - 
sistema que, como vimos, era o alvo das críticas da contracultura -, não podemos esquecer que os nossos autores não só não deixaram de lado, mas, pelo contrário, trouxeram de volta à tona a "velha retórica da intransigência”, analisada por Albert Hirschman e que pautou nossas análises do discurso de Nathan Glazer e Irving Kristol. Pois, como ensinava Max Weber, sem o recurso de "um ponto de vista" que implique valores, como seria possível selecionar, no fluxo intrincado daquilo que ocorre, o que merece ser ressaltado, analisado, descrito (Boltanski; Chiapello, 1999)?

\section{A CRÍTICA DE NATHAN GLAZER AO WELFARE STATENOS ESTADOS UNIDOS}

Nathan Glazer, com The Limits of Social Policy (1988), torna-se um dos grandes nomes do pensamento neoconservador, da crise do liberalismo reformador, a partir de uma crítica veemente às políticas do New Deal rooseveltiano, encaradas como ideologias que incitam a população a assumir uma postura conflituosa e revolucionária que, ao fim e ao cabo, engendraria a decadência da sociedade americana.

O combate de Nathan Glazer às políticas econômicas e sociais que formam o moderno Welfare State ressalta o seu efeito perverso, afirmando que "há um sentimento generalizado de que enfrentamos uma crise na política social", diante da qual "nossos próprios esforços para lidar com o sofrimento aumentam o sofrimento". (Hirschman, 1995, p.30).

Segundo Hirschman, para argumentar a favor dessa desanimadora conclusão, Glazer não recorreu a modelos de computador; em vez disso, enumerou algumas razões sociológicas simples. As políticas de bem-estar social, ponderou, têm o objetivo de lidar com problemas que eram tratados por estruturas tradicionais, como a família, a Igreja ou a comunidade local. Quando tais estruturas desmoronam, o Estado intervém para assumir suas funções. Nesse processo, ele enfraquece ainda mais o que resta das estruturas tradicionais. Surge daí uma necessidade maior de assistência pública do que a prevista, e a situação piora, em vez de melhorar (1995).

Glazer, apesar de ter trabalhado em diversos programas sociais, passa a afirmar que, com tempo, percebeu que aqueles projetos estavam provocando mais problemas do que trazendo soluções (1992). Para ele, as inovações realizadas a partir de uma excessiva confiança na capacidade de planejamento social acabaram tendo como resultado a decadência social.

Para Glazer, as medidas tomadas nas últimas décadas com o intuito de implantar serviços sociais nacionais uniformes entraram em conflito com a realidade da diversidade étnica, racial e local. A seu ver, o ambicioso esforço para incorporar a assistência social dentro de um sistema nacional, representado pelos planos propostos pelo presidente Nixon (o Plano de Assistência Familiar) e pelo presidente Carter (o Programa para Melhores Empregos e Ingressos), fracassou. Ao se debruçar sobre as causas desse fracasso, Glazer encontra, na singularidade dos Estados Unidos, as causas da inviabilidade do Welfare State em suas fronteiras (1992).

Os Estados Unidos, para Glazer, são diferentes porque, em comparação com países com sistemas de bem-estar bem desenvolvidos, têm uma grande massa de população pobre e geradora de problemas, tais como o grande número dos delitos, o desemprego dos jovens entre as minorias, as famílias rotas e de filhos ilegítimos e a precária condição de suas moradias (1992). Para o neoconservador, a raça é uma das importantes causas do fracasso das políticas sociais, uma vez que tais comportamentos - abandono do trabalho, famílias encabeçadas por uma mulher, ilegitimidade - são muito mais frequentes entre a população negra. Situação agravada pelo fato de que a população americana, nos anos 60, é constituída, em grande medida, por negros e outros grupos, como o dos porto-riquenhos (1992).

Para Glazer, nas décadas de 60 e 70, os negros e os imigrantes asiáticos e sul americanos, devido às políticas sociais, ficaram ainda mais de- 
pendentes da assistência social, passando a ameaçar a posição econômica avançada atingida pelos Estados Unidos e provocando, portanto, a desordem social e o aumento das desigualdades (1992). Emerge, assim, o perigo de que os despossuídos passem a rebelar-se contra a indústria e a ordem (1992). A desordem social tem sido, a seu ver, a via escolhida e insuflada pela cultura progressista, pela contra cultura, pela Nova Esquerda e pelas minorias favoráveis a um sistema nacional de política social completamente desenvolvido (1992). Está em pauta, aqui, o perigo da democracia proveniente dos movimentos sociais dos anos 60 , acalentando a crença na revolução da igualdade que, ao mesmo tempo em que eleva as expectativas de novas políticas sociais, aumenta o mar da miséria (1992).

Os benefícios das políticas sociais redundam na expectativa cada vez maior das massas, que passam a querer também a revolução da igualdade. Para Glazer, essa é a força mais poderosa do mundo moderno, identificada apenas por Tocqueville, capaz de dimensionar a sua impressionante potência. Num primeiro momento, os despossuídos expressam uma demanda de igualdade nos direitos políticos e no poder político, seguindo depois a demanda de igualdade de poder econômico, status social e autoridade em todas as esferas (Glazer, 1992). Notamos, assim, a centralidade da retomada dos ensinamentos de Tocqueville por Glazer, principalmente em sua denúncia de que a paixão da igualdade acaba por contaminar e inflamar até mesmo os ociosos, as mulheres e os camponeses, que passam a nutrir “ambições desenfreadas", trazendo um grande perigo às democracias (Tocqueville, 1998). Em seus mais importantes livros, A democracia na América e O Antigo Regime e a Revolução, Tocqueville, nostálgico do "mundo vencido pela Revolução Francesa", deparando-se com a "inevitável marcha para a igualdade", traz para o centro de seu pensamento o esforço incessante de atrelá-la à concepção aristocrática de liberdade. A nosso ver, o subtítulo mesmo da obra em que analisa a "Revolução Americana”, leis e costumes, traduz o seu objetivo de impedir o total desaparecimento do Antigo Regime, por meio de uma legislação e da manutenção dos valores inerentes ao mundo aristocrático, ameaçado com o avanço da equalização de condições (1998). Glazer, na esteira de Tocqueville, sustenta a tese de que a sociedade estadunidense vive um período de decadência e que é necessário reconstituir as condições para que aquela melhoria anterior reapareça. Sendo assim, defende a desconstrução das políticas de bem-estar, responsáveis pelo enfraquecimento dos valores tradicionais, uma vez que as medidas do Welfare State, além de serem ineficientes para a resolução dos problemas sociais que justificam a sua implementação, corroboram o seu aumento.

Notamos, assim, que Glazer considera ineficientes as políticas sociais, acusando-as tanto por sua inutilidade quanto por seu efeito perverso de aumentar os problemas que se propõe a resolver. Hirschman, ao analisar a estrutura do discurso dos intelectuais americanos que revigoram a retórica reacionária durante a conjuntura dos anos 70, a partir do ataque das políticas econômicas e sociais que constituem o moderno Welfare State, desenvolve algumas teses que, a nosso ver, contribuem para a apreensão dos argumentos de Glazer. Há a tese da inutilidade, que afirma serem nulas todas as tentativas de transformações sociais, e a tese da perversidade, que parte do pressuposto de que toda ação deliberada para romper com a ordem política, social e econômica é abortiva, pois, na tentativa de impor à sociedade uma direção determinada, consegue fazê-la movimentar-se, só que na direção oposta à almejada, servindo apenas para exacerbar os fatores que ela deseja solucionar (Hirschman, 1995). Assim, para Glazer, a revolução da igualdade, além de provocar o aumento da miséria, tem dado origem a outras formas de desigualdade: os clientes das medidas de bem-estar versus os trabalhadores pobres; os receptores da seguridade social versus os contribuintes da seguridade social; os empregados do Governo versus os empregados do setor privado. Sendo assim, o slogan da igualdade acaba levando a um conjunto de novas contradições, levantando pai- 
xões, levando ao descontentamento, e não será jamais realizado (Glazer, 1992, p.14-15).

Glazer, além de afirmar que a causa de problemas como a pobreza são os próprios movimentos sociais, que reivindicam o aumento da ação do Estado para a melhoria das condições da população, também condena o fato de que, nos Estados Unidos, a essência do pensamento liberal frente à política social é pôr a culpa não nos infortunados que sofrem o problema social, mas na sociedade e no sistema político americanos que trabalham pela sua solução. O mandamento liberal é: para cada problema existe uma política, e, inclusive, ainda que o problema seja novo, o sistema social e a política têm de ser culpados por nada terem feito antes sobre ele. Diversamente, a Inglaterra responsabiliza os pobres por sua pobreza, admitindo a sua falta de vontade de trabalhar, ou seja, atribui aos despossuídos os seus próprios problemas (1992).

Sendo a América marcada por grandes diferenças relacionadas com a raça e as etnias, os sistemas nacionais baseados no seguro e na dignidade, que tratam todos como iguais, não podem funcionar nos Estados Unidos do mesmo modo que na Europa ou no Japão, segundo Glazer (1992). Quando existem amplas diferenças em uma população - diferenças raciais ou étnicas relacionadas com diferenças no acesso, na produtividade, na cultura e nos valores -, torna-se difícil a introdução de um sistema nacional e uniforme de assistência social (1992). A assistência social acaba por corroborar os problemas sociais, provocando a decadência dos valores tradicionais da sociedade americana, comprometendo a origem dos imigrantes brancos e livres, que chegam à América à procura de trabalho duro, independentemente da assistência do governo. A população pobre e negra, ao contrário, não apenas se acostuma às benesses do Welfare State, como passa a nutrir expectativas cada vez maiores, exigindo mais e mais auxílios e provocando a decadência da sociedade americana.

Dentre as políticas sociais criticadas por Nathan Glazer, em seu artigo "A Constituição e a diversidade americana”, receberão destaque aque- las que dizem respeito ao combate da segregação racial. Tanto assim que, no bicentenário da Constituição americana, ele ataca com veemência o fato de ela ser totalmente omissa em relação à diversidade racial (Glazer, 1988). Para ele, a enorme diversidade religiosa, racial e étnica do país dificulta sobremaneira a elaboração de uma solução pacífica para a sua proteção. E, duzentos anos depois de elaborada a Constituição, constata que a diversidade americana tem se expandido sob o impacto de seiscentos mil imigrantes por ano, principalmente da Ásia e da América Latina (1988).

Nathan Glazer condena, nesse sentido, a proibição constitucional e legal da segregação, apoiada por aqueles que estavam empenhados em superar a discriminação contra negros (e certos outros grupos minoritários). Em sua leitura, tais medidas acabaram por reforçar o preconceito e a discriminação, uma vez que, antes das ações afirmativas, um regime de discriminação e de preconceito contra negros e asiáticos coexistia muito bem com associações, igrejas, escolas e assemelhados, mantidos por esses grupos.

Para analisarmos a argumentação de Glazer, não podemos perder de vista que, apesar dos princípios igualitários da república norte-americana, mesmo após a abolição, negros e brancos formavam mundos à parte. Essa realidade de segregação passa a ter um fundamento legal a partir de uma decisão da Suprema Corte, em 1896, que considerava constitucional a existência de acomodações separadas para brancos e negros em transportes públicos, desde que fossem equiparáveis. A filosofia do "igual, mas separado" erigiu uma barreira, negando aos não-brancos o livre acesso à moradia, restaurantes e à maior parte dos serviços públicos.

Durante toda a primeira metade do século $\mathrm{XX}$, a rigidez da classificação racial, a segregação e a discriminação contra a população negra acirraram as relações raciais, sendo causa de inúmeros enfrentamentos nos principais centros urbanos. Isso levou a uma polarização da sociedade americana: por um lado, os grupos a favor da integração racial e, por outro, os segregacionistas que a consideravam constitucional, e, portanto, legítima, não 
vendo razões para mudanças do status quo. Pressionado pela participação da sociedade civil, o Congresso americano aprovou, em 1964, o Civil Rights Act (Lei dos Direitos Civis) que, além de banir todo o tipo de discriminação, concedeu ao governo federal poderes para implementar a dessegregação. Nesse contexto, surgem as políticas de ação afirmativa na América do Norte.

O termo ações afirmativas foi primeiramente empregado em 1961, durante o governo Kennedy, que estabeleceu um comitê para estudar a questão das oportunidades iguais no mercado de trabalho. Em 1965, o presidente Lyndon Johnson passa a exigir das empresas que recebiam contratos do governo federal um tratamento nãodiscriminatório no emprego e um programa de ações afirmativas que visassem a combater os efeitos da discriminação passada. Dois anos depois, a categoria sexo passou a ser usada como critério para ações afirmativas e, em 1972, as mesmas exigências passaram a vigorar também nas instituições educacionais. Essa orientação do governo federal marca um esforço significativo de implementar uma política que fosse além de uma postura de antidiscriminação passiva. Ela traduz uma intenção de usar o poder público em benefício de vítimas de discriminação social. Os programas de ação afirmativa deveriam apresentar objetivos e procedimentos claros, que explicitassem um esforço no sentido de equalizar as oportunidades de emprego. Assim, passa a ser solicitada, tanto para firmas como instituições educacionais, a elaboração de planos de ação afirmativa, e são estabelecidas sanções oficiais para o caso de não-cumprimento dessa exigência (Washington; Harvey, 1989).

Glazer critica com veemência as ações afirmativas, condenando a decisão Brown sobre a segregação dos negros nas escolas públicas em 1954. Em 1951, um caso judicial havia sido iniciado contra o Distrito Escolar da cidade de Topeka, Kansas, em um distrito judicial do Estado, em nome de Linda Brown, uma aluna da terceira série que era forçada a caminhar 1,6 quilômetros para estudar em uma escola para afro-americanos, enquanto que uma escola para alunos brancos estava distante apenas sete quateirões de sua casa. Em 1954, na decisão Brown vs. Board of Education, a Suprema Corte acabou com a segregação nas escolas. No entanto, devido à resistência social, a decisão de Brown levou quinze anos para ser implementada. Numa das principais contendas, o governador do Arkansas, Orval Faubus, preferiu fechar uma escola do estado a cumprir a decisão judicial que mandou matricular alunos negros, tendo sido necessária uma intervenção com tropas federais para que a escola fosse reaberta.

Para Glazer, embora a decisão Brown tenha sido proclamada em nome da proteção à diversidade, acabou suscitando um conjunto diferente de conflitos que acabou opondo os direitos individuais aos direitos de grupo. Constata, então, que, devido às decisões da Suprema Corte, as matrículas por critérios de raça, para crianças da maioria e de minorias, tornaram-se comuns, sendo que crianças satisfeitas com suas escolas foram transferidas, por critério de raça, para outras escolas, só para que, em cada escola, fosse estabelecido um equilíbrio, embora as comunidades desejassem que seus filhos permanecessem perto de casa e que fossem educados entre os de seu próprio grupo (Glazer, 1988).

Essas comunidades, segundo Glazer, sentiram-se lesadas porque perderam a capacidade de preservar certos vínculos estreitos entre seus membros, comprometendo a sua sobrevivência como comunidades distintas. Ele critica tenazmente, então, o fato de a Constituição não defender esses diversos direitos, a seu ver fundamentais à preservação comunitária, condenando o impacto de se mandar os filhos de uma comunidade para escolas que são selecionadas simplesmente para que seu grupo proporcione nelas uma maioria "em favor dos negros" (1988).

Glazer condena também as medidas constitucionais contra a segregação nos transportes escolares que, como no caso de São Francisco, em que crianças chinesas de origem mexicana foram incluídas nos ônibus de condução escolar para compor um ambiente integrado em favor dos negros, fato que acabou ocasionando sérios e violen- 
tos conflitos (1988).

Assim, ele passa a condenar os efeitos das políticas de integração nas escolas negras segregadas do Sul. Para Glazer, os esforços para a que fosse criada uma educação que, de algum modo, refletisse o grupo segregado acabou pondo fim não apenas à capacidade de o grupo negro preservar a sua diversidade (1988), como também a de outros grupos que anteriormente tinham uma capacidade maior de preservar sua diversidade.

Glazer (1975), baseando seu argumento no fato de que os EUA são o primeiro país a se definir, não em termos de origem étnica, mas em termos de adesão a regras comuns de cidadania, considera inconstitucionais as políticas governamentais, que justificam o que ele chama de discriminação afirmativa, ou seja, o favorecimento de minorias com o fim de alcançar o objetivo da igualdade. Ele diz estar surpreso com o fato de que políticas que reverteram o consenso de dois séculos de história americana pudessem se estabelecer de forma tão poderosa no espaço de uma década. Para Takaki (1994), asiático-americano e professor da Universidade da Califórnia, os críticos das políticas de ação afirmativa, muitas vezes, omitem o fato de que, através da história norte-americana, houve sempre discriminação positiva para homens brancos, que se beneficiaram, durante muito tempo, de oportunidades educacionais e profissionais que lhes eram reservadas.

As medidas constitucionais contra a segregação nos transportes escolares, matéria de educação na ótica de Glazer, acabaram gerando conflitos de outra natureza outrora inexistentes, configurando um efeito perverso das políticas sociais. Ou seja, há aqui a defesa explícita da manutenção da segregação que existia anteriormente.

Glazer acaba chegando à sua tese geral quanto aos limites das políticas sociais, ou seja, de "que a política social criou, em quase todos os campos, demandas novas e ingovernáveis”. O que está em pauta aqui é que uma política educacional contra a segregação teve como efeito - perverso - criar conflitos de outra ordem: o desmantelamento das comunidades tradicionais. Podemos, assim, notar que a síntese feita por Glazer com relação ao efeito perverso das políticas sociais, no livro que o consagra como neoconservador, aplica-se à sua crítica às ações afirmativas:

Em nossas políticas sociais estamos tratando de
fazer frente ao desmoronamento das formas tra-
dicionais de fazer frente à desgraça. Estas vias tra-
dicionais estão localizadas principalmente na fa-
mília, mas também no grupo étnico, nos vizinhos,
na igreja (Glazer, 1992, p.13, tradução minha).
Em nossos esforços para fazer frente ao desmoro-
namento destas estruturas tradicionais, nossas
políticas sociais o que estão fazendo/conseguin-
do é debilitá-las ainda mais e fazendo com que,
em alguns aspectos, as coisas fiquem ainda pior.
Não estamos obtendo firmes progressos contra o
mar de miséria. Nossos esforços para enfrentar a
miséria e a desgraça estão apenas tendo como
resultado o seu aumento (1992, p.13-14, tradu-
ção minha).

A tese da ameaça, que, segundo Hirschman, é central na retórica conservadora revigorada nos anos 70, sustenta que, embora a mudança proposta talvez seja desejável em si, acarreta custos ou consequências inaceitáveis de outro tipo (Hirschman, 1995), está presente na argumentação de Glazer. Para ele, o aumento dos gastos com assistência social durante o período da Grande Sociedade-com o sistema de assistência médica, com os subsídios à habitação, à educação e à compra a crédito, com a guerra contra a pobreza -, provocando a expansão da política social americana no final dos anos 60 e nos anos 70, foi acompanhado pelo aumento do desemprego juvenil, pelo abandono do trabalho por parte dos homens das minorias e por uma crescente ruptura das famílias negras. Sendo assim, a maior disponibilidade de recursos para a assistência acabava estimulando o desemprego, o ócio e a desintegração da família, fatores que ela visava a combater (Glazer, 1992).

Apesar de tais medidas terem sido aplicadas originalmente para implementar os direitos dos negros, segundo Glazer, os próprios negros colocam em dúvida se a educação imposta pela Corte Suprema do Estado é a educação que eles queriam para seus filhos. Olham, assim, com nostalgia, para muitas das escolas durante o período da segregação, porque elas eram instituições da comunidade negra (1988). 
Outro aspecto levantado por Glazer, no que diz respeito à questão de comunidade e seu relacionamento com a integração escolar, refere-se à diferença de valores, orientação e comportamento. A seu ver, as demais comunidades podem simplesmente repudiar a intimidade com negros ou apresentar motivos de caráter predominantemente religioso ou moral, como o fato de as escolas não poderem ensinar religião, adotar normas de recato no vestir ou impor uma disciplina escolar tradicional, tratando de criar escolas privadas (academias segregadas) como reação às decisões judiciais de integração (1988). As ações afirmativas geram, assim, na leitura de Glazer, um conflito maior, opondo as comunidades conservadoras às liberais.

Não há dúvida de que as comunidades conservadoras dos Estados Unidos se sentem hoje ameaçadas em consequência da expansão dos direitos civis e das liberdades civis. Também as comunidades liberais se sentem ameaçadas pela mobilização dos tradicionalistas. Por um lado, a expansão de direitos é vista como a concessão ao indivíduo da maior liberdade possível-e, nessa liberdade, os indivíduos podem criar as subcomunidades que quiserem, sejam elas tradicionais ou radicais, convencionais ou não-convencionais. Por outro lado, considera-se essa expansão como uma arrogante extensão de valores e comportamentos que ameaçam as comunidades tradicionais, de forma a não poderem proteger intrusões que eles consideram nocivas, e que as impedem de oferecer o ambiente que desejam para seus filhos. Foi essa reivindicação feita por Yoder ao se recusar a obedecer às leis de matrícula escolar obrigatória do Estado de Wisconsin; é uma reivindicação hoje suscitada por um grande setor da população americana que se apega aos valores tradicionais. Como resultado, outros indivíduos e comunidades, caracterizados por valores liberais e progressistas, sentem que estão ameaçados em seus estilos de vida. O conflito irrompe por toda parte: quando a Cidade de Nova York insiste em que suas instituições que prestam serviços sociais não devem discriminar homossexuais - e a Igreja Católica, que presta tais serviços, afirma que a religião não pode contem- porizar com tal proibição; quando comunidades e Estados utilizam todos os meios para burlar a constitucionalização do aborto declarada pela Suprema Corte; quando comunidades e associações de bairros buscam formas de proibir "cinemas para adultos" ou de retirar das bibliotecas escolares livros com linguagem sexual explícita. E a lista pode ser ampliada (Glazer, 1988).

Nesse embate, o neoconservador posicionase enfaticamente em defesa da tradição, em defesa das comunidades conservadoras dos Estados Unidos que estão sendo ameaçadas pelas políticas de combate à segregação social. O centro da crise reside, a seu ver, na ruptura das estruturas elementares - família, grupo étnico, bairro, igreja -, muito mais eficientes na produção de motivações e constrangimentos que orientariam o comportamento dos indivíduos em direção à independência, à sua capacidade de conquistar e manter seu lugar na sociedade sem auxílio de políticas sociais.

O enaltecimento da tradição americana por Glazer parece desconsiderar totalmente que os problemas sociais eram resolvidos, então, por meios institucionais repressivos. Mesmo quando a escravidão, anteriormente inscrita na Constituição, é abolida no final da guerra civil através da $13^{\mathrm{a}}$ emenda, de 1965, os sulistas negros são forçados a entrar num sistema de servidão em alguns aspectos muito pior. Eles continuam sendo cidadãos de segunda classe, deixando de servir aos interesses dos senhores de escravos para serem submetidos aos dos barões do norte (Lazare, 1998).

A proposição da retomada da tradição por Glazer, em nome da manutenção da ordem existente, se faz sem qualquer questionamento da reinvenção das formas de segregação racial e do protecionismo econômico, mas também fora de suas fronteiras por sua política imperialista e de extermínio dos Estados Unidos. A seu ver, a sociedade americana, antes da revolução dos direitos civis nos anos 60 e 70, vivia sem conflitos, uma vez que a Constituição americana garantia a suposta existência natural da segregação. Como vimos na argumentação do neoconservador, as ações afirmativas e os movimentos sociais são os responsáveis pelo aumento dos 
conflitos raciais, étnicos e religiosos. A solução por ele proposta estaria na defesa da segregação, que sustenta a excepcionalidade natural dos imigrantes livres e brancos do norte, capazes de manter sob o seu controle a herança da discriminação que está sendo contestada nos anos 60. Os pobres, negros, porto-riquenhos e asiáticos põem em risco a superioridade americana e os seus valores tradicionais, familiares e religiosos. A excepcionalidade americana está ameaçada pelas medidas que contestam a discriminação. O seu revigoramento só virá com a retomada da segregação.

Glazer critica a Constituição americana pelo fato de ela ser omissa com relação à diversidade étnica e não por ela legitimar a escravidão. Frente a essa suposta omissão, ele propõe, no Bicentenário da Constituição, a retomada dos valores tradicionais destruídos pelas políticas contrárias à discriminação dos anos 60, particularmente pelos negros, esses sim, naturalmente violentos, criminosos e vagabundos. Ele está, então, explicitando a defesa de medidas municipais e locais que reinventem a segregação racial, impedindo a infecção da excepcional sociedade americana por aqueles naturalmente degenerados. $\mathrm{O}$ aparente paradoxo de sua argumentação é que ele diz estar atuando em nome da diversidade como um valor americano. Se o que querem os negros é tornarem-se iguais aos brancos, eles estarão, assim, comprometendo a diversidade americana. Em seu nome, Glazer, defende a manutenção de toda a sorte de desigualdade, como "o retorno à harmonia primordial do liberalismo do século XIX".

\section{IRVING KRISTOL: política, moral e virtude republicana}

Irving Kristol é o primeiro editorialista do Wall Street Journal. Extremamente nacionalista, ele atribui o problema da América à política internacional, ou seja, ao re-planejamento da missão dos Estados Unidos no mundo, em um momento em que é colocada em xeque a sua singular situação providencial no mundo pelos intelectuais corruptores dos valores tradicionais americanos.

Em seu artigo intitulado "O espírito de 87", que faz parte da coletânea em comemoração aos duzentos anos da Constituição Americana, publicada originalmente no The Public Intrest $\mathrm{n}$. 86, Kristol começa por assinalar a excepcionalidade dos Estados Unidos, por ser resultante da união de controles institucionais para o estabelecimento de uma comunidade política e de uma "fé democrática". A "veneração" da Constituição pelo povo americano, desde os primórdios da nação até os dias atuais, a seu ver, tão marcados pela secularização, é a essência de sua singularidade (Kristol et al, 1988).

A alegada excepcionalidade da Constituição Americana deve-se, na leitura de Kristol, não apenas ao fato de ela ser a mais antiga e eficaz, mas por ser também diferente em espécie. Segundo Kristol, a Bandeira, a Declaração e a Constituição americanas constituem a trindade santa do que Tocqueville chamou a religião cívica americana. Portanto, existe um espírito da Constituição, impregnando o texto e transformando-o num documento pactuante e reverenciado em um pilar da religião cívica americana. A ideia de povo americano como comunidade pactuante, governada por representantes eleitos, vem, segundo Kristol, do Calvinismo, do Puritanismo e do Presbiterianismo, e não de lembranças de um parlamento feudal como na Europa. Embora a Constituição tenha tido muitos pais intelectuais - Locke, Montesquieu, panfletários republicanos britânicos do século XVIII, os constitucionalistas da época, bem como $\mathrm{s}$ filósofos escoceses do Iluminismo - ela teve, a seu ver, uma única mãe espiritual, a Religião Protestante (Kristol et al, 1988).

Para Kristol, na esteira de Adam Smith, a peculiaridade americana não reside apenas nesse matrimônio, mas também no fato de ele gerar como filho legítimo o empenho dos americanos em ganhar dinheiro e adquirir propriedades para melhorar suas condições. A Constituição Americana está, assim, inextricavelmente vinculada à ideia de progresso econômico e à crença de que uma vida passada na busca legal da riqueza e dos rendimen- 
tos poderia ser uma vida justa.

Kristol ressalta, então, que a Constituição Americana, por vincular estreitamente a ideia de progresso econômico e a justiça, passa a ser a própria expressão da religião civil, o que lhe garante o endosso moral, e não apenas utilitário, da sociedade. Nesse sentido, ele retoma os ensinamentos do infinitamente sábio Tocqueville, por enaltecer o fato de os americanos considerarem a religião como indispensável para a manutenção das instituições republicanas (Kristol et al, 1988).

Para Kristol, a ciência e a filosofia, além de não poderem oferecer as verdades morais pertinentes à tradição religiosa, só contribuem para fomentar o cepticismo sobre elas. O alvo de Kristol, que, como vimos, defende o estreito vínculo entre a busca legal de riquezas e as virtudes morais, são os intelectuais eruditos que, na esteira de Charles A. Beard, fomentam o cepticismo frente à Constituição que, para eles, estava a serviço de interesses pecuniários, repudiando os princípios da Declaração de Independência. Para o professor Charles A. Beard, a Constituição norte-americana de 1787 foi elaborada por homens abastados, que tinham interesses a proteger, o que somente seria possível se eles, os Convencionais de Filadélfia, criassem um governo forte, para substituir o governo frouxo do regime confederativo. No Capítulo V de seu livro American Government and Politics, Beard analisa os arquivos e os documentos da época, demonstrando que Abraham Baldwin até Robert Yates, todos eles tinham apólices, interesses mobiliários, interesses imobiliários, eram homens ricos como Washington, o homem mais rico do seu tempo, e que não houve representação das classes menos favorecidas na Convenção.

Os intelectuais que concordam com os estudos de Beard estavam, segundo Kristol, corrompendo, assim, os valores tradicionais americanos e desconsiderando a veneração popular à Constituição, por considerá-la ilusória (1988, p.6). Ele está aqui condenado o movimento conhecido como contracultura, que se baseava fundamentalmente na contestação dos valores e costumes da sociedade norte-americana de então, a partir de uma pers- pectiva de esquerda, que se disseminou nos campi universitários dos Estados Unidos durante as décadas de 1960 e 1970. Muitos daqueles que viriam a ser denominados de neoconservadores interpretavam esse movimento como uma rejeição radical dos valores, atitudes e objetivos americanos tradicionais, o que era visto por eles como algo a ser combatido (Kirkpatrick, 2004).

A despeito desses intelectuais, contudo, para Kristol, a maioria esmagadora dos americanos ainda concordaria com George Washington quando ele salientou, no Discurso de Despedida, o estreito laço entre a moralidade e a religião (Kristol et al, 1988). Apesar de os resultados das pesquisas de opinião (não demonstrados por Kristol) estarem evidenciando que os americanos são mais religiosos que os povos da Europa Ocidental, o fato de essa religiosidade estar estreitamente relacionada tanto com a prosperidade e a estabilidade políticas americanas quanto com o espírito de patriotismo americano, segundo a análise de Kristol, continua sendo ignorado. Isso tem provocado a secularização e o enfraquecimento cada vez maior da religião civil, que vem sendo vulgarizada por aqueles que concebem a sociedade americana apenas como uma sociedade burguesa, ou seja, como uma sociedade aquisitiva, onde floresce a livre empresa (1988).

Os detratores dos valores tradicionais americanos, segundo a leitura de Kristol, interpretam a sociedade americana como uma versão moderna da cidade dos porcos de Platão e acabam por incitar um ânimo antiburguês, levando, por um lado, a juventude a um hedonismo libertário, próximo da licenciosidade, e, por outro, a população adulta à insegurança frente aos seus valores. Essas atitudes estão pondo em risco as tradições constitucionais americanas, que sempre expressaram o excepcional "impulso protestante para melhorar a condição econômica de uma pessoa”. A política da ordem constitucional dos Estados Unidos, segundo Kristol, foi internalizada pelos americanos como intrinsecamente vinculada à realização de um objetivo econômico justo, de acordo com um padrão de vida estável, e não como a busca de uma 
ideologia ou causa. Essa constatação de Kristol é feita curiosamente durante suas aulas sobre a Constituição, onde, a seu ver, apenas os poucos alunos europeus ou latino-americanos conseguiam entender a sentido da pergunta feita por ele com relação aos interesses representados pelo Congresso americano. Pois, para os imigrantes, é explícito o fato de que, nos Estados Unidos, a Constituição vincula a prosperidade americana à cidadania como causa e efeito, ou seja, representa os interesses econômicos de todos os seus eleitores. Para Kristol, configura-se, assim, a excepcionalidade e a singularidade americanas pautadas na crença de que uma vida mais justa está associada à prosperidade econômica. Há uma devoção burguesa expressa na diferença entre o presbiteriano John Knox e Benjamin Frankilin, uma vez que os pressupostos desse último estão ancorados, na leitura de Kristol, na conciliação da secularização dos interesses burgueses com as virtudes morais e religiosas. São elas que permitem que as gerações de imigrantes integrem-se ao pacto americano, entendido como a aceitação das devoções burguesas calcadas na promessa de uma vida melhor (Kristol et al, 1988).

Para Kristol, é então essa devoção burguesa entendida como a premissa da política americana, mesmo em tempos de crise econômica, como foi emblemático nos dias da grande Depressão, que deve atuar agora como antídoto à ideia do socialismo, que ameaça a paz e a tradição americanas. Deve haver um juramento de cidadania pelos novos imigrantes, acostumados com o fato de que os seus representantes eleitos representam essencialmente seus partidos e a sua ideologia ou causa, identificados equivocadamente com o interesse público (1988, p.14).

Kristol rechaça, então, o comunismo, principalmente pelo fato de ele atentar contra a ordem internacional estabelecida, na qual os Estados Unidos são o sol do sistema capitalista. O anticomunismo da direita intelectual americana emerge, assim, como uma forma de colocar os EUA acima de tudo, atuando como se faltasse democracia no mundo e sobrasse nos Estados Unidos (Miguel, 1978).
Há, nesse sentido, a retomada da retórica conservadora - particularmente a de Tocqueville-, procurando soluções para a crise de governabilidade, característica dessa fase do capitalismo, procurando, então, dimensionar o papel que passam a exercer os Estados Unidos e quais os desafios e soluções para que seu país possa manter o status de grande potência mundial. A solução encontrada pelo pensamento neoconservador reside na necessidade de se restabelecer a virtude cívica, tão enaltecida no século XIX por Tocqueville, na prática política, com o intuito de se combater, através de vias políticas, aquilo que era percebido como a decadência de valores que poderia colocar em risco a própria democracia norte-americana. A ideia original de democracia envolveria a obrigação de educar a população para a virtude republicana intrinsecamente vinculada ao ideal nacional norte-americano e ao caráter heroico atribuído ao significado dos Estados Unidos como nação, que podem ser colocados em risco pela degradação dos valores morais e pelo niilismo individual e social (Teixeira, 2007).

O patriotismo americano ganha primazia no pensamento de Kristol por ser um patriotismo não baseado no território, mas em ideais e princípios universais, representados pela própria Constituição dos Estados Unidos. O pensamento neoconservador reporta-se a uma determinada visão acerca das origens dos Estados Unidos, que enxerga esse país como portador de valores universais, para combinar, de uma forma inusitada, um sentimento nacionalista com uma predisposição internacionalista disposta a defender ativamente tais valores.

Para o credo conservador (Miguel, 1978), a aceitação dos valores de equidade, liberdade e igualdade de oportunidades, na esteira dos Pais Fundadores, da Constituição Americana e dos ensinamentos de Tocqueville, deveria vir acompanhada da recusa do igualitarismo. E o respeito pelos valores tradicionais da família e da religião seria alcançado pela recusa da contracultura e do radicalismo universitários, uma vez que a democracia americana não pode subsistir muito tempo em um mundo que é hostil aos valores americanos. 
Kristol defende, assim, a moralização da política norte-americana a partir da crença americana de que os princípios da Declaração de Independência são verdades universais, duradouras e autoevidentes. Desse modo, seria natural, a partir desse ponto de vista, que os Estados Unidos assumissem uma postura de missão civilizadora no mundo, a qual estava sendo posta à prova, internamente, pela contracultura, pelos imigrantes, pelos negros e pobres e, externamente, pelo comunismo. Revigora-se, então, a excepcionalidade americana como antídoto ao alegado efeito perverso do Welfare State e à decadência moral, provocados pela Nova Esquerda, pelo comunismo, pelos pobres, particularmente os negros e imigrantes.

A retomada do papel da virtude republicana está respaldada na ideia dos Pais Fundadores dos Estados Unidos, que enxergavam a nação não como um fim em si mesma, mas como um meio para realizar seus ideais de liberdade, o que tornaria os Estados Unidos uma força para o bem do mundo, o que, portanto, não se limita às fronteiras nacionais. Os neoconservadores atribuem, assim, aos Estados Unidos uma espécie de missão civilizadora no mundo, devido à superioridade da civilização americana. Segundo Teixeira, a ideia do excepcionalismo americano é assim retomada e levada a seu limite (Teixeira, 2007).

Neste sentido, Kristol defende a reverência, a devoção e a lealdade à Independência e à Constituição americanas como expressão do credo neoconservador que enaltece o Preito de Lealdade à Bandeira e à República que ela representa. Insiste na importância do significado da palavra recitação como um exercício de uma consagração solene da realização da extraordinária Declaração de Independência. Na suas palavras:

O bicentenário da Constituição Americana me parece uma ocasião apropriaḑa não simplesmente para celebrações, não simplesmente para receber reflexões, mas para dedicar uma prece em favor da Constituição. É de se presumir que ninguém seja contra. (Kristol et al, 1988, p.14)

\section{CONSIDERAÇÕES FINAIS}

Para Kristol, o que os intelectuais de verdade têm de fazer é apoiar a ordem capitalista e o poder imperial dos Estados Unidos (Teixeira, 2007), inscrevendo-se como o primeiro em tão satisfatória cruzada. Vários foram seus seguidores, uma vez que, diante da crise vivida pelos EUA nos anos 70 , os neoconservadores defendem a necessidade de retomar o "espírito das leis" norte-americanas, fazendo parte daqueles que veneram a Constituição como o pilar da mais remota e, ainda, maior democracia política da terra" (Lazare, 1998). A alusão de Daniel Lazare a uma afirmação do presidente Bill Clinton, em 1997, de que "o que está errado com a América" pode ser consertado pelo "que há de certo na América", parece sintetizar a solução conservadora proposta por Glazer e Kristol, dentre vários outros neoconservadores, para a superação da crise americana, por expressar a natureza solipsista da política americana.

O pensamento neoconservador, nos Estados Unidos, pode ser tratado como um conjunto organizado de ideias, embora, como em todo pensamento político, exista uma série de divergências. Aqui, procuramos enfatizar alguns dos principais denominadores comuns da argumentação dos dois autores examinados, Nathan Glazer e Irving Kristol, que enaltecem a excepcionalidade americana calcada na virtude cívica, segundo a qual o Estado deve voltar a adaptar-se às predisposições conservadoras da sociedade, mediante a defesa contundente da família e da religião e o combate tenaz ao Welfare State.

(Recebido para publicação em outubro de 2009) (Aceito em fevereiro de 2010)

\section{REFERÊNCIAS}

BEARD, Charles A. American government and politics. New York: The MacMillan Company, 1910.

BOLTANSKY, Luc; CHIAPELLO, Ève. O novo espírito do capitalismo. São Paulo: Martins Fontes, 2009.

FANON, F. Os condenados da terra. Rio de Janeiro: Paz e Terra, 1968. 
GLAZER, N. Affirmative discrimination. New York: Basic Books, 1975.

A constituição e a diversidade americana. In: KRISTOL, Irving et al. A ordem Constitucional Americana - 1787/1987. Rio de Janeiro: Forense-Universitária 1987.

Los limites de la politica social. Madri: Ministério de Trabajo y Seguridad Social, 1992.

HIRSCHMAN, A. O. A retórica da intransigência: perversidade, futilidade, ameaça. São Paulo: Companhia das Letras, 1995.

JACOBY, R. Os últimos intelectuais. São Paulo: Trajetória Cultural/Edusp, 1987.

KIRKPATRICK, J. Neoconservatism as a response to counterculture, In: STELTEZER, I. (Org.). The neocon reader. New York: Grove Press, 2004.

KRAMNICK, I. Apresentação In: HAMILTON, A.; JAY, J.;

MADISON, J. Os Artigos Federalistas - 1787-1788. Rio de Janeiro: J. Villeneuve e Comp. [1841] 1987.
LAZARE, D. America the undemocratic. New Left Review, n.232, nov./dez., 1998

MIGUEL, A. El poder de la palabra: lectura sociológica de los intelectuales em Estados Unidos. Madrid: Editorial Tecnos, 1978

TAKAKI, R. Reflections on racial pattern in America. In: From different shores: perspective on race and ethnicity in America. New York: Oxford University Press, 1994.

TEIXEIRA, C. G. P O pensamento neoconservador em política externa nos Estados Unidos. 2007. Dissertação (Mestrado) - PUC. São Paulo, 2007.

TOCQUEVILLE, Alexis de A democracia na América. São Paulo: Martins Fontes, 1998.

WASHINGTON, V.; HARVEY, W. Affirmative rethoric, negative action. East Lansing, MI: ASHE-ERIC, 1989. 


\section{HUES OF NORTH AMERICAN POLITICAL THOUGHT IN THE CONSERVATIVE TURN OF 1970}

\section{Maria Ribeiro do Valle}

This paper examines how the reinvigoration of the exceptional American historical experience appears as a solution to some of the leading neoconservatives, considering Nathan Glazer and Irving Kristol as emblematic, regarding the "fall" of the American empire, beginning in the 1960s and 1970s, after its rise during the Cold War, the so-called 25 glorious years. We note that the arguments of these authors is rooted in the revival of reactionary rhetoric as an antidote to the decadence of American virtue supposedly caused by Communism, by the counterculture movement and the alleged perverse effect of the welfare state.

KeYwords: neoconservatives, American exceptionalism, post 25 glorious years, counterculture, welfare state.

\section{TON DE LA PENSÉE POLITIQUE NORD- AMÉRICAINE LORS DU TOURNANT CONSERVATEUR DE 1970}

\author{
Maria Ribeiro do Valle
}

Cet article analyse comment la relance de l'expérience historique américaine exceptionnelle surgit comme une solution aux yeux de quelques néoconservateurs de premier plan, Nathan Glazer et Irving Kristol étant emblématiques face à la "chute" de l'empire américain, qui a commencé dans les années 1960 et 1970, après son ascension au cours de la Guerre Froide, les dites 25 années glorieuses. Nous pouvons constater que les arguments de ces auteurs sont enracinés dans la reprise de la rhétorique réactionnaire utilisée comme un antidote à la décadence de la vertu américaine soi-disant causée par le communisme, par le mouvement de contreculture et par le prétendu effet pervers de l'État providence.

Mots-CLÉs: néoconservateurs, exceptionnalité américaine, l'après des 25 années glorieuses, contre culture, l'État-providence (welfare state).

Maria Ribero do Valle - Doutora pelo Departamento de Ciências Sociais Aplicadas da Faculdade de Educação da Unicamp. Professora do Departamento de Sociologia da Faculdade de Ciências e Letras da Unesp - campus de Araraquara. Editora da revista Estudos de Sociologia do departamento de Sociologia e do programa de pós-graduação em sociologia da Unesp - Araraquara. Acaba de concluir seu Pósdoutorado no IFCH - Unicamp, com a pesquisa Pensamento político norte-americano na virada conservadora da década de 1970 - alguns matizes e, quem sabe, algumas matrizes. Publicou: 1968: o dialogo é a violência: movimento estudantil e ditadura militar no Brasil (Editora da Unicamp), em 1999, que acaba de ter sua segunda edição lançada; A Violência Revolucionária em Hannah Arendt e Herbert Marcuse (Editora Unesp), em 2006. 